\author{
Marquette University \\ e-Publications@Marquette
}

College of Nursing Faculty Research and

Publications

Nursing, College of

$7-2020$

\title{
Development and Psychometric Analysis of the Patient Preferences for Engagement Tool
}

Teresa Jerofke-Owen

Marquette University, teresa.jerofke@marquette.edu

Mauricio Garnier-Villarreal

Marquette University, mauricio.garniervillarreal@marquette.edu

Follow this and additional works at: https://epublications.marquette.edu/nursing_fac

Part of the Nursing Commons

\section{Recommended Citation}

Jerofke-Owen, Teresa and Garnier-Villarreal, Mauricio, "Development and Psychometric Analysis of the Patient Preferences for Engagement Tool" (2020). College of Nursing Faculty Research and Publications. 759.

https://epublications.marquette.edu/nursing_fac/759 
Marquette University

e-Publications@Marquette

\title{
Nursing Faculty Research and Publications/College of Nursing
}

This paper is NOT THE PUBLISHED VERSION; but the author's final, peer-reviewed manuscript. The published version may be accessed by following the link in the citation below.

Nursing Research, Vol. 69, No. 4 (July/August 2020): 289-298. DOl. This article is (C) Wolters Kluwer Health, Inc. and permission has been granted for this version to appear in e-Publications@Marquette. Wolters Kluwer Health, Inc. does not grant permission for this article to be further copied/distributed or hosted elsewhere without the express permission from Wolters Kluwer Health, Inc.

\section{Development and Psychometric Analysis of the Patient Preferences for Engagement Tool}

\author{
Teresa A. Jerofke-Owen
}

Assistant Professor, College of Nursing, Marquette University, Milwaukee, Wisconsin

Mauricio Garnier-Villarreal

Research Assistant Professor, College of Nursing, Marquette University, Milwaukee, Wisconsin

\begin{abstract}

\section{Background}

Assessing patients' preferences for engaging in healthcare is needed to inform the planning and delivery of individualized healthcare. Unfortunately, patients are often not engaged in their care to the extent that they would like, leading to patient feelings of disempowerment and frustration.
\end{abstract}

Objectives

The purpose of this study was to (a) develop and (b) psychometrically test the Patient Preferences for Engagement Tool (PPET), a clinical assessment tool that can be used by nursing staff to identify patient preferences for engagement in healthcare. The usability of the PPET was also examined for both nurses and patients participating in the study. 


\section{Methods}

The psychometric evaluation design used content and construct validity testing (exploratory and confirmatory factor analysis, known groups comparisons) and reliability estimation using Cronbach's alpha coefficient. The sample consisted of 308 adult patients aged 18-101 years from a Midwestern U.S. Magnet-designated academic medical center.

\section{Results}

Content validity index was at least 0.8 for all but one item. Using a split sample, a six-factor solution was first identified using exploratory factor analysis and then confirmed using confirmatory factor analysis. Demographic and illness factors were not significant predictors of factor scores. Cronbach's alpha coefficients of all six factors were $>0.7$. Both patients and nurses gave high ratings to the tool on effectiveness, efficiency, and satisfaction with use.

\section{Discussion}

The PPET demonstrated acceptable validity and reliability estimates. Assessing patient preferences for engagement gives value to the patient voice and provides an opportunity to have discussions with patients about various ways they can engage in their healthcare. Future research will focus on reducing the number of items on the PPET to construct a clinically useful resource for providers to use to assess patient preferences for healthcare engagement, leading to the development of more personalized care delivery methods.

Acknowledging and involving patients as members of the healthcare team to promote safety and improve the patient experience has been integral in the shift to consumer-oriented healthcare (Patient-Centered Outcomes Research Institute, 2013). Patients can engage in their care through various modalities, including knowledge sharing, information gathering, collaborating with providers to set goals and modify care plans, decision-making, attending and participating in daily rounds, mobilizing the expertise and support of family and friends, and utilizing various features of electronic health records (EHRs) (Agency for Healthcare Research and Quality, 2013; Swartwout, Drenkard, McGuinn, Grant, \& El-Zein, 2016). Engaging patients in their care during hospitalization has been associated with a $50 \%$ reduction in adverse events, improved patient satisfaction, greater confidence in treatment choices, and participation in self-management behaviors (Dwamena et al., 2012; Weingart et al., 2011).

Although prior research has examined the patient experience of engagement (Boivin et al., 2018; Graffigna \& Barello, 2018), little research has focused on patients' preferences for how they actually want to engage in their care (Prey et al., 2014). Prior research has demonstrated that there is not a routine assessment of patient preferences for engagement (Rozenblum et al., 2011) and that patients are not being involved in the process of care planning (Jordan, 2014; Rosewilliam, Roskell, \& Pandyan, 2011). Patients have described barriers to engagement in their care, including frustrations that no opportunities for decisions were offered to them, uncertainty in an unfamiliar environment, constant new faces, hospital policies, and the perception that nurses are too busy to interrupt (Jerofke-Owen \& Dahlman, 2019). These findings provide evidence toward the value of improving the patient experience of engagement.

The patient engagement experience may take different forms across patient populations (Selman et al., 2017; Tobiano, Marshall, Bucknall, \& Chaboyer, 2015), highlighting the need to assess patients' individual preferences for engagement. Younger age, higher education levels, female gender, and a more favorable view of health status have all previously been associated with wanting a more active role in healthcare (Florin, Ehrenberg, \& Ehnfors, 2008; Hawley \& Morris, 2017; Hoerger, Chapman, Mohile, \& Duberstein, 2016), suggesting the importance of individualizing patient engagement efforts. Engagement should also be viewed 
across a continuum, where some patients may prefer a more passive role, such as simply wanting to be informed of the plan, whereas some patients may prefer a more active role, such as monitoring for changes in health status, making treatment decisions, or creating goals with the healthcare team (Carman et al., 2013). Patients may, however, have a hard time articulating what their preferences for care are or even bringing them up in the first place, without their providers initiating the conversation (Etkind, Bone, Lovell, Higginson, \& Murtagh, 2018).

Many of the instruments that have been used to assess patient preferences for engagement have focused solely on preferences for treatment decision-making such as the Patient Attitudes and Beliefs Scale (Arora, Ayanian, \& Guadagnoli, 2005), the Autonomy Preference Index (Ende, Kazis, Ash, \& Moskowitz, 1989), the Control Preferences Scale (Degner, Sloan, \& Venkatesh, 1997), and the Decisional Engagement Scale (Hoerger et al., 2016). The Patient Preferences for Patient Participation tool (Eldh, Luhr, \& Ehnfors, 2015) assesses patient preferences for engaging in communication, knowledge sharing, planning, and managing self-care but does not include items relating to information gathering, goal setting, decision-making, family involvement, participation in rounds, and informatics. The Patient Preferences for Patient Participation tool was also tested in a small, homogenous sample, limiting the generalizability of the initial psychometric properties (Luhr, Eldh, Nilsson, \& Holmefur, 2018).

The Patient Preferences for Engagement Tool (PPET) was developed because, at the time of development, there were no other published, psychometrically tested tools that encompassed the extensive components of the concept of patient engagement. The purpose of this study was to (a) develop and (b) psychometrically test the PPET, which can be used by clinical nurses to assess patient preferences for multiple aspects of engagement in their healthcare and help direct more personalized care. The usability of the PPET was also examined for both nurses and patients participating in the study.

\section{METHODS}

\section{Study Design and Participants}

This psychometric evaluation study was conducted in four sequential steps:

1. content validity assessment of items;

2. construct validity testing using a split sample approach for identification of factor structure using exploratory factor analysis (EFA), confirmation of factor structure using confirmatory factor analysis (CFA), and known groups analysis;

3. reliability testing; and

4. usability testing.

The convenience sample was recruited from eligible hospitalized patients from eight medical, surgical, and oncology units within a 516-bed Magnet-designated academic medical center in the Midwestern United States between July 2017 and February 2018. Eligible patients were at least 18 years of age, could speak and understand English, and were able to provide consent. Patients were not enrolled if they were identified as a definite or possible discharge on enrollment days, as the PPET was meant to help inform nursing staff of patient preferences for engagement during hospitalization and administration on the day of discharge would not have provided full benefit. Ten patients were asked to participate in the content validity testing portion of the study; patients were selected because they were considered the experiential experts and part of the targeted population for the instrument (Mokkink et al., 2018). Four hundred patients were approached for the construct validity portion of the study, and 337 patients (84.3\%) consented to participate. Of the 337 patients who consented to be in the study, complete data were collected from 308 patients (91.4\%). A little over a third of 
patients (117) completed a patient usability survey, and 166 nurses (53.54\%) who had a patient participating in the study completed the nurse usability survey (the same nurse could have completed the survey multiple times).

\section{Measurements}

\section{Demographics}

Patients were asked to self-report age, their chronic illness diagnoses (which were then tallied together to get a total number to measure load), gender, marital status, whether they live alone, race, number of hospitalizations in last year, and education level. Health perception was measured by asking patients, "How would you rate your health in general? $1=$ poor, 2 = fair, $3=$ good, 4 = very good, $5=$ excellent.

\section{Patient Preferences for Engagement Tool}

The PPET was constructed using data from an extensive review of the literature and qualitative data from an earlier study of the patient experience of engagement during hospitalization (Jerofke-Owen \& Dahlman, 2019). In addition, strategies for patient and family engagement highlighted in the Agency for Healthcare Research and Quality (2013) Guide to Patient and Family Engagement in Hospital Quality and Safety (an evidence-based resource) were incorporated during item development. Seventeen patients from seven medical, surgical, and oncology units were interviewed. Patients ranged in age from 19 to 83 and had multiple comorbidities, including hypertension, coronary artery disease, cancer, and diabetes. Thirteen of the patients were White, and 11 had more than a high school education. The initial 29 individual items within the PPET were developed from patient stories of how they engaged in their care or how they would have liked to engage in their care and were in line with aspects of engagement that were discussed in the literature. Items related to participating in the following aspects of care: medication administration; medication and treatment decision-making; sharing past experiences and/or feelings; receiving information about treatments, medications, or diagnostic tests; involving family and friends in care; using EHRs; participating in support groups or rounds; comfort in speaking up; accessing/obtaining resources (both written and electronic); collaborating with providers; goal setting; selfmonitoring; incorporating spiritual beliefs; and asking questions. All items were scored on a 5-point Likert rating scale $(1=$ strongly disagree and $5=$ strongly agree $)$. The Flesch Kincaid Grade Level Readability Test demonstrated that the items were written at an eighth-grade level.

\section{Assessment of Usability Survey (RN and Patient Forms)}

These eight-item surveys were constructed by the study's principal investigator to capture three components of ISO's 9241-11 (International Standardization for Organization, 1998) definition of usability: (a) effectiveness, (b) efficiency, and (c) satisfaction. Item content was similar in the RN and patient forms for six of the eight items but worded for the respective respondent (see Table 1). Two items were unique to each survey. All eight items were scored on a 5 -point Likert scale $(1=$ strongly disagree and $5=$ strongly agree $)$. An open-ended question was used to assess for any usability issues not captured in the items.

TABLE 1: Assessment of Usability Item Descriptions and Means

\begin{tabular}{|l|c|l|l|l|l|}
\hline Nurse survey & & & Patient survey & & $n$ \\
\hline Item description & $n$ & $\begin{array}{l}\text { Mean } \\
\text { (SD) }\end{array}$ & Item description & $\begin{array}{l}\text { Mean } \\
\text { (SD) }\end{array}$ \\
\hline Helpful in planning my care & 166 & $\begin{array}{l}3.7 \\
(1.0)\end{array}$ & $\begin{array}{l}\text { Discussing my answers to the items } \\
\text { with the nurses will be helpful to my } \\
\text { care }\end{array}$ & 114 & $\begin{array}{l}4.1 \\
(1.0)\end{array}$ \\
\hline $\begin{array}{l}\text { Incorporated PPET13 preferences in } \\
\text { my nursing care }\end{array}$ & 165 & $\begin{array}{l}3.7 \\
(1.1)\end{array}$ & - & & \\
\hline
\end{tabular}




\begin{tabular}{|c|c|c|c|c|c|}
\hline $\begin{array}{l}\text { Satisfied with how long it took me to } \\
\text { review item responses on the PPET }\end{array}$ & 164 & $\begin{array}{l}3.8 \\
(1.0)\end{array}$ & Took too long to complete & 116 & $\begin{array}{l}1.8 \\
(1.0)\end{array}$ \\
\hline Provided me with useful information & 166 & $\begin{array}{l}3.9 \\
(1.0)\end{array}$ & $\begin{array}{l}\text { Provided my nurse with useful } \\
\text { information about me }\end{array}$ & 115 & $\begin{array}{l}4.1 \\
(1.0)\end{array}$ \\
\hline Had too many items (reverse coded) & 166 & $\begin{array}{l}2.8 \\
(1.1)\end{array}$ & Had too many items (reverse coded) & 117 & $\begin{array}{l}1.9 \\
(1.1)\end{array}$ \\
\hline $\begin{array}{l}\text { Helped me think about ways to } \\
\text { engage my patient in care }\end{array}$ & 165 & $\begin{array}{l}3.7 \\
(1.0)\end{array}$ & $\begin{array}{l}\text { Helped me think about ways I could } \\
\text { engage in my care }\end{array}$ & 117 & $\begin{array}{l}4.1 \\
(1.0) \\
\end{array}$ \\
\hline $\begin{array}{l}\text { Feel PPET will improve nursing care I } \\
\text { deliver to patients }\end{array}$ & 162 & $\begin{array}{l}3.5 \\
(1.0)\end{array}$ & - & & \\
\hline $\begin{array}{l}\text { Provided opportunity to talk with } \\
\text { patients about engagement in their } \\
\text { care }\end{array}$ & 162 & $\begin{array}{l}3.5 \\
(1.1)\end{array}$ & $\begin{array}{l}\text { Provided an opportunity to talk with } \\
\text { my nurse about my engagement in } \\
\text { care }\end{array}$ & 115 & $\begin{array}{l}3.9 \\
(1.1)\end{array}$ \\
\hline- & & & Items were easy to understand & 117 & $\begin{array}{l}4.6 \\
(0.7)\end{array}$ \\
\hline- & & & $\begin{array}{l}\text { I believe my answers to the items } \\
\text { may change over time }\end{array}$ & 115 & $\begin{array}{l}3.3 \\
(1.2)\end{array}$ \\
\hline
\end{tabular}

\section{Data Collection}

Ethics approval for the study was obtained from both the participating university and the hospital system. Trained research assistants-who were nursing students-enrolled patients into the study following a thorough explanation of the study's purpose and the patients' rights.

The 10 patients in the content validity assessment portion of the study were selected at random from the unit census board. Before entering the patient room, we verified with the nurse that the patient would be appropriate to act as a content expert (alert and oriented, stable, participatory). The patient experts were provided with the definition of patient engagement and asked to rate each item of the PPET using the 4-point rating sale ( 1 = not relevant, 2 = somewhat relevant, 3 = quite relevant, and 4 = very relevant $)$.

Patients completed the demographic form electronically, via an iPad. Patients completed the PPET on a paper copy so that patients' answers could be shared with the nurses caring for the patients. The PPET answers were entered into the electronic database by the research assistants. Paper usability surveys were left with patients and the patients' nurses, with instructions to complete them upon patient discharge from the hospital. Patients were instructed to place completed usability surveys in a sealed envelope and give them to their nurses, who placed them in a collection box, along with their own completed usability surveys.

\section{Data Analysis}

Data analysis was performed using R. Missing demographic data for regression analyses ( $<5 \%$ for any given variable) was handled with multiple imputation, improving parameter recoverability, reducing bias, and increasing power (Enders, 2010). The content validity index (CVI) was calculated by determining the proportion of the 10 patients who rated each item a " 3 " or " 4 " on the CVI survey (Lynn, 1986).

For construct validity analysis, given that the items on the PPET were derived from an extensive review of the literature and patient interview data, we first used EFA to identify the best data-driven factorial structure, using maximum likelihood estimation and quartimin oblique rotation. That way, we are evaluated the objective of an EFA (identify the underlying factor structure) instead of the commonly misused method of principal component analysis, which seeks to explain the largest amount of variance with the components (Park, Dailey, \& Lemus, 2002). The number of factors was chosen based on appropriate fit indices and practice relevance. To validate 
the structure inferred from the EFA, a cross-validation CFA using structural equation modeling in $\mathrm{R}$ was conducted. The sample was randomly split into two even halves ( $n=154$ each). The first half was used for the EFA, and the second half was used for the cross-validation CFA.

All the items from the PPET were scored on an ordered 5-point Likert scaling format and treated as ordered categorical instead of continuous data. We followed the categorical CFA approach that analyzes the data using polychoric correlations between ordered items (Bovaird \& Kozoil, 2012). Data were analyzed with the diagonal weighted least squares estimator, with mean and variance-adjusted standard errors and chi-square statistic. Goodness of fit was assessed using numerous indices, as different indices often reflect different features of models. Although there are no set rules for evaluating goodness of fit, the following indices and their parameters were used to determine goodness of fit: chi-square, comparative fit index (CFI) > .9, Tucker-Lewis index $(T L I)>.95$, root-mean-square error of approximation (RMSEA) <.06, standardized root-mean-square residual $(S R M R)<.08$, and gamma-hat $>.95$ (Hu \& Bentler, 1999). Reliability was evaluated using Cronbach's coefficient alpha.

Once the factorial structure was determined, we estimated a latent regression in one comprehensive model, where the PPET factors were predicted by age in years, chronic illness load (number of self-reported chronic illness diagnoses), gender (male/female), whether the patient lived alone (yes/no), education level (grouped as less than high school, high school, at least some college), and health perception (5-point rating scale).

\section{RESULTS}

\section{Content Validity Testing}

The content validity of the PPET was assessed by 10 medical and surgical patients with a mean age of 66.3 years ( $S D=22.0$, range: $26-94$ years). Sixty percent of patients were female, $30 \%$ were married, $66.7 \%$ were White, $60 \%$ lived alone, $80 \%$ had at least some college education, $50 \%$ had been previously hospitalized over the last year, $60 \%$ self-rated their health as "fair," and 40\% self-rated their health as "good." The CVI (Lynn, 1986) was $>.80$ for 28 of the 29 items. One item that pertained to the interest in attending support groups had a CVI of .56. The decision was made to keep the item in about support groups for psychometric testing, but to further examine how the item correlated with other items, as the four patients who rated it as not relevant or somewhat relevant did so because they personally did not think support groups would be helpful to their care. The 10 content experts did not provide any additional qualitative data to change or improve the tool; therefore, items were left as they were initially worded.

\section{Sample Characteristics}

In total, 308 patients completed the PPET following content validity testing. As shown in Table 2, participants had a mean age of 58.2 years ( $S D=17.1$, range: $18-101$ years). Slightly more than half of the study participants were married (51.9\%), and the majority were White (77.9\%), lived with at least one other person (76.5\%), and had more than a high school education (67.9\%). Less than a quarter of the patients (21.9\%) self-reported their health to be excellent or very good.

TABLE 2: Participant Characteristics

\begin{tabular}{|l|l|l|l|r|}
\hline & $n$ & $\%$ & Mean (SD) & \multicolumn{1}{l|}{ Range } \\
\hline Age & & & $58.2(17.1)$ & $18-101$ \\
\hline Total chronic illness diagnoses & & & $2.1(1.7)$ & $0-9$ \\
\hline Diagnoses & & & & \\
\hline Hypertension & 107 & 34.7 & & \\
\hline Heart disease (valve, coronary, congenital) & 75 & 24.4 & & \\
\hline
\end{tabular}




\begin{tabular}{|c|c|c|c|c|}
\hline Dyslipidemia & 63 & 20.5 & & \\
\hline Asthma & 34 & 11.0 & & \\
\hline COPD & 26 & 8.5 & & \\
\hline Diabetes mellitus & 70 & 22.7 & & \\
\hline Arthritis & 53 & 17.2 & & \\
\hline Cancer & 83 & 26.6 & & \\
\hline \multicolumn{5}{|l|}{ Gender } \\
\hline Male & 132 & 42.6 & & \\
\hline Female & 175 & 56.5 & & \\
\hline \multicolumn{5}{|l|}{ Marital status } \\
\hline Married & 161 & 51.9 & & \\
\hline Single & 76 & 24.5 & & \\
\hline Divorced/separated & 38 & 12.3 & & \\
\hline Widowed & 29 & 9.4 & & \\
\hline Other & 6 & 1.9 & & \\
\hline \multicolumn{5}{|l|}{ Live alone } \\
\hline Yes & 73 & 23.5 & & \\
\hline No & 237 & 76.5 & & \\
\hline \multicolumn{5}{|l|}{ Race/ethnicity } \\
\hline Asian & 2 & 7 & & \\
\hline African American & 51 & 16.8 & & \\
\hline Hispanic & 8 & 2.6 & & \\
\hline White & 236 & 77.9 & & \\
\hline Other & 6 & 2.0 & & \\
\hline \multicolumn{5}{|l|}{ Educationlevel } \\
\hline$<$ High school & 27 & 8.8 & & \\
\hline High school graduate & 71 & 23.3 & & \\
\hline Some college/specialized training & 88 & 28.9 & & \\
\hline College graduate & 94 & 30.8 & & \\
\hline Graduate degree & 25 & 8.2 & & \\
\hline \multicolumn{5}{|l|}{ Prior hospitalization within last year } \\
\hline Yes & 212 & 70.7 & & \\
\hline No & 88 & 29.3 & & \\
\hline \multicolumn{5}{|l|}{ Self-rated health } \\
\hline Poor & 49 & 16.1 & & \\
\hline Fair & 87 & 28.5 & & \\
\hline Good & 102 & 33.4 & & \\
\hline Very good & 52 & 17.0 & & \\
\hline Excellent & 15 & 4.9 & & \\
\hline
\end{tabular}

Note. PPET = Patient Preferences for Engagement Tool; COPD = chronic obstructive pulmonary disease.

\section{PPET Item Analysis}

In the construct validity testing sample, item means for the 29 items ranged from $2.8(S D=1.5)$ to $4.9(S D=0.5)$. Items with the highest means pertained to wanting to know why things are done, wanting to know about medications before taking them, wanting to learn how to take care of health at home, and wanting to be given options before deciding on one treatment. Items with the lowest means pertained to attending support groups, discussing and creating goals with nursing staff, receiving written information about health, and being present 
during rounds. One item was removed from the tool before EFA, as it was the only negatively worded item, and reversed items tend to lead to problematic responses and poor model fit (Weijters, Baumgartner, \& Schillewaert, 2013). Another item asking if the patient wanted to have spiritual/religious beliefs incorporated into their care was removed because it demonstrated scoring at the extremes of the scale (either $1 \mathrm{~s}$ or $5 \mathrm{~s}$ ) and did not fit well within the model. Validity and reliability testing for the PPET was conducted on the remaining 27 items.

\section{Exploratory Factor Analysis}

The EFA was estimated for one to nine factors, and the respective fit indices are shown in Table 3. Review of the fit indices revealed that the data required at least five factors to properly represent the data, but the seven-, eight-, and nine-factor models presented estimation problems. Joining data from the prior qualitative study, practice experience, and data-driven information, the chosen structure was the six-factor model. The six factors were labeled as Information Gathering (IG), Self-Advocacy (SA), Informed Decision-Making (IDM), Family Involvement (FI), Active Participation (AP), and Resources (RE). Looking at the explained variance in each of the 27 items ( $R 2$ ), we see that the six-factor model explained, on average, $45 \%$ (mean $=0.45, S D=0.15$, median $=$ 0.46 ) of the variance in the items, ranging from $15 \%$ to $69 \%$.

TABLE 3: Fit Indices for Exploratory Factor Analysis Models

\begin{tabular}{|l|l|l|l|l|l|l|l|}
\hline Factors & $\chi^{2}(\mathrm{df})$ & CFI & TLI & RMSEA & SRMR & Gamma-hat & Gamma-hat $_{\text {adj }}$ \\
\hline 1 & $847.7(324)$ & 0.544 & 0.506 & 0.104 & 0.097 & 0.793 & 0.759 \\
\hline 2 & $701.9(298)$ & 0.648 & 0.586 & 0.095 & 0.083 & 0.833 & 0.788 \\
\hline 3 & $568.8(273)$ & 0.742 & 0.669 & 0.085 & 0.070 & 0.872 & 0.822 \\
\hline 4 & $461.1(249)$ & 0.815 & 0.739 & 0.075 & 0.057 & 0.905 & 0.855 \\
\hline 5 & $382.5(226)$ & 0.864 & 0.788 & 0.068 & 0.049 & 0.928 & 0.879 \\
\hline 6 & $297.4(204)$ & 0.919 & 0.860 & 0.055 & 0.041 & 0.956 & 0.918 \\
\hline 7 & $243.4(183)$ & 0.947 & 0.899 & 0.047 & 0.038 & 0.971 & 0.940 \\
\hline 8 & $200.8(163)$ & 0.967 & 0.929 & 0.039 & 0.034 & 0.982 & 0.957 \\
\hline 9 & $163.8(144)$ & 0.983 & 0.958 & 0.030 & 0.032 & 0.990 & 0.974 \\
\hline
\end{tabular}

Note. $\mathrm{CFI}=$ comparative fit index; TLI = Tucker-Lewis index; RMSEA = root-mean-square error of approximation; $\mathrm{SRMR}=$ standardized root-mean-square residual.

IG content (three items) pertains to aspects of care such as being informed of vital signs, lab, or test results or receiving written information about one's health. SA content (four items) pertains to aspects of care such as comfort in asking questions, speaking up if something does not seem right, repeating information from one provider to another, and asking why things are done. IDM content (six items) pertains to aspects of care such as making decisions about new medications after learning risks and benefits; choosing when to do things while hospitalized, such as walking, showering, and learning about health; and choosing treatments based on options. $\mathrm{Fl}$ content (two items) pertains to aspects of care such as wanting the questions and concerns of family answered and educating family members on how to best help patients take care of themselves. AP content (seven items) pertains to aspects of care including sharing past experiences of care, sharing how one subjectively feels, conversing with nursing staff during handoff, participating in rounds, discussing goals with nursing staff, monitoring for changes in health status, and learning how to better care for oneself. RE content (five items) pertains to aspects of care such as accessing lab and test results in one's EHR, sending questions through the EHR, completing advanced directives, accessing websites and blogs, and attending support groups. 


\section{Confirmatory Factor Analysis}

Once the EFA structure was chosen, we performed a cross-validation CFA, which presented proper overall model fit, $\chi 2(309)=453.35, \mathrm{CFI}=0.892, \mathrm{TLI}=0.878, \mathrm{RMSEA}=0.056,90 \% \mathrm{Cl}[0.045,0.067], \mathrm{SRMR}=0.125$, gamma-hat $=$ 0.933 , gamma-hatadj $=0.918$. Factor loadings and correlations matched the EFA results and theoretical interpretation. To have a full representation of the model, CFA was then estimated for the full sample. This model also presented a good overall model fit, $\chi 2(309)=607.61, \mathrm{CFI}=0.833, \mathrm{TLI}=0.81, \mathrm{RMSEA}=0.056,90 \% \mathrm{Cl}$ $[0.049,0.062]$, SRMR $=0.101$, gamma-hat $=0.933$, gamma-hatadj $=0.918$. Our gamma-hat, adjusted gamma-hat, and RMSEA show good fit; however, CFI and TLI are on the lower side. The lower CFI and TLI estimations may be due to small correlations between items, which generate artificially low CFI and TLI values. Local fit was evaluated with modification indices, and there were no meaningful local fit modifications needed.

Figure 1 presents the factors loadings and correlations between the factors. All factor loadings were medium to high and statistically significant, with the lowest being 0.3 and the highest being 0.921 . $R 2$ values between .094 and .848 (with an average of $.49, S D=.18$ ) indicate that the constructs explained at least $9 \%$ of the variance in the items, on average explaining $49 \%$ of the variance of the items. All six of the factors were positively correlated with each other at $p<.01$, meaning as item scores for one factor increased, item scores in another factor also increased. The strongest correlation was between IDM and SA $(r=.84)$, whereas the weakest correlation was between FI and IDM $(r=.40)$.

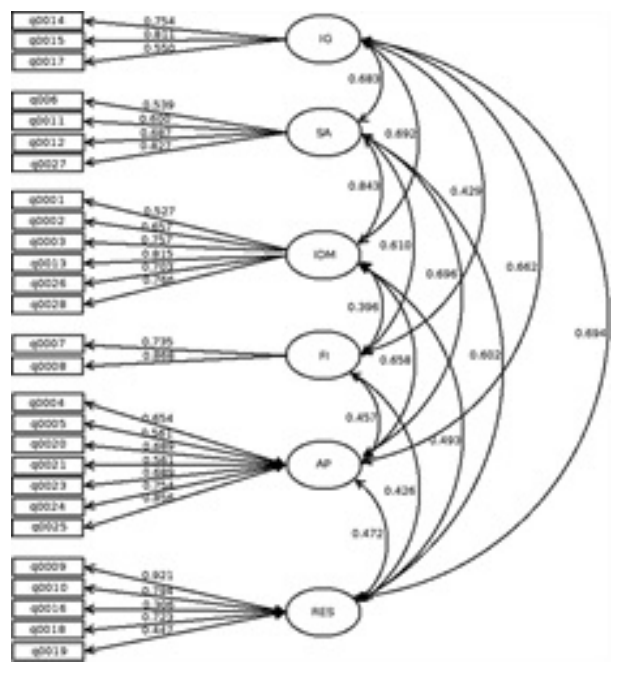

FIGURE 1: Factor loadings of items and correlations between factors.

\section{Reliability Testing}

Cronbach's alpha reliability coefficients were >.70 for all six factors: IG (.72), SA (.75), IDM (.85), FI (.76), AP (.84), and RE (.72). A coefficient alpha of .70 and above is considered acceptable for new instruments (Mokkink et al., 2018).

\section{Known Groups Validity Testing}

The latent regression model did not significantly predict any of the PPET factor scores (see Table 4). In addition, the explained variances of each of the factors were lower than $9 \%$, which represents a small effect based on the large amount of predictors. Age was a significant individual predictor of the $\operatorname{RE}$ factor $(\beta=-0.01, S E=0.005, p=$ $.05)$ and $\mathrm{FI}$ factor $(\beta=0.011, S E=0.005, p=.038)$. Older patients were more likely to score their preferences lower for items in the RE factor and higher for items in the $\mathrm{FI}$ factor. 
TABLE 4: Latent Regressions

\begin{tabular}{|c|c|c|}
\hline & $\beta(S E)$ & $p$ \\
\hline \multicolumn{3}{|c|}{ Information Gathering $\left(R^{2}=.033\right)$} \\
\hline Age & $0.004(0.005)$ & .46 \\
\hline Education & $-0.042(0.221)$ & .85 \\
\hline Perceived health & $-0.009(0.095)$ & .93 \\
\hline Chronic illness & $0.086(0.074)$ & .24 \\
\hline Gender & $-0.010(0.223)$ & .97 \\
\hline Living situation & $-0.216(0.255)$ & .40 \\
\hline \multicolumn{3}{|c|}{ Self-Advocacy $\left(R^{2}=.031\right)$} \\
\hline Age & $0.009(0.006)$ & .16 \\
\hline Education & $-0.089(0.226)$ & .70 \\
\hline Perceived health & $-0.051(0.101)$ & .61 \\
\hline Chronic illness & $-0.011(0.064)$ & .86 \\
\hline Gender & $-0.129(0.231)$ & .58 \\
\hline Living situation & $-0.197(0.252)$ & .43 \\
\hline \multicolumn{3}{|c|}{ Informed Decision-Making $\left(R^{2}=.076\right)$} \\
\hline Age & $-0.011(0.006)$ & .06 \\
\hline Education & $-0.133(0.199)$ & .50 \\
\hline Perceived health & $0.120(0.090)$ & .18 \\
\hline Chronic illness & $0.069(0.055)$ & .21 \\
\hline Gender & $0.215(0.206)$ & .30 \\
\hline Living situation & $-0.325(0.212)$ & .13 \\
\hline \multicolumn{3}{|c|}{ Family Involvement $\left(R^{2}=.070\right)$} \\
\hline Age & $0.011(0.005)$ & .04 \\
\hline Education & $-0.122(0.219)$ & .58 \\
\hline Perceived health & $0.009(0.099)$ & .93 \\
\hline Chronic illness & $0.001(0.067)$ & .99 \\
\hline Gender & $-0.086(0.209)$ & .68 \\
\hline Living situation & $-0.498(0.240)$ & .04 \\
\hline \multicolumn{3}{|c|}{ Active Participation $\left(R^{2}=.022\right)$} \\
\hline Age & $0.001(0.005)$ & .83 \\
\hline Education & $-0.162(0.184)$ & .38 \\
\hline Perceived health & $0.079(0.082)$ & .34 \\
\hline Chronic illness & $0.039(0.059)$ & .51 \\
\hline Gender & $0.030(0181)$ & .87 \\
\hline Living situation & $-0.225(0.219)$ & .30 \\
\hline \multicolumn{3}{|l|}{ Resources $\left(R^{2}=.090\right)$} \\
\hline Age & $-0.010(0.005)$ & .05 \\
\hline Education & $0.353(0.197)$ & .07 \\
\hline Perceived health & $-0.014(0.085)$ & .87 \\
\hline Chronic illness & $-0.042(0.058)$ & .46 \\
\hline Gender & $-0.261(0.196)$ & .18 \\
\hline Living situation & $-0.151(0.214)$ & .48 \\
\hline
\end{tabular}




\section{Usability Testing}

Patients and nurses viewed the PPET positively (see Table 1). Item scores pertaining to the tool's effectiveness, efficiency, and satisfaction all averaged above 3.5 (indicating that patients and nurses both agreed more with the statement than disagreed). Patients reported that the items were easy to understand $(M=4.6, S D=0.7)$ and that they provided useful information about them to their nurses $(M=4.1, S D=1.0)$. Nurses also reported that the PPET was helpful in planning their patients' care $(M=3.7, S D=1.0)$ and, more importantly, helped them think about ways to engage their patients in their care $(M=3.7, S D=1.0)$. Patients believed that their answers might change over time on the survey, stressing the need to repeatedly assess patient preferences for engagement as patients navigate the healthcare system.

\section{DISCUSSION}

The emphasis of patient engagement in healthcare, as a mechanism to improve patient outcomes and the patient care experience, has become a main driver for quality improvement efforts of many organizations (Clancy, 2011; James, 2013; Pelletier \& Stichler, 2013). With the adoption of the new mindset of providing care "with" patients and family and not "for" patients and families has come the necessity to take the time to ask how patients and families want to engage in their care in order to better individualize care (Bombard et al., 2018). This study demonstrated acceptable measures of validity and reliability of the PPET in a sample of hospitalized patients with numerous medical diagnoses and comorbidities. The PPET is the first psychometrically tested instrument to measure patient preferences for numerous components of engagement inclusive in one survey, including decision-making, communication, collaboration with providers, accessing electronic resources and medical records, involving family and/or friends in care, self-advocacy, and sharing subjective information. Patients may prefer to engage in one aspect of their care while being disinterested in another. Administering an instrument that is selective to one aspect of engagement may not capture the entirety of patient preferences for engagement, leading to patient frustrations. Patient engagement in healthcare should be viewed as a continuum (Carman et al., 2013), stressing the importance of measuring patient preferences for multiple components of the engagement process.

Measuring patient preferences for engagement places value on the patient voice and helps to inform the delivery of individualized care. Nurses must be educated about the importance of assessing their patients' preferences for engagement in healthcare, as patients may often not be comfortable sharing their preferences on their own (Etkind et al., 2018). Jerofke-Owen and Dahlman (2019) conducted a qualitative study with hospitalized patients on their experiences engaging in their care. Patients reported that they never truly thought about different ways they could be involved in their care beyond treatment decision-making. A timely assessment of patient preferences for engagement in care is also important to avoid providing care that does not match with patient expectations or expecting patients to do something out of their comfort zone-which ultimately leads to disempowerment or feelings of lack of respect or frustration (Frank, Asp, \& Dahlberg, 2009). Nurses must also be educated about the value of involving patients in their care (Drenkard, Swartwout, Deyo, \& O'Neil, 2015), as patient engagement can be viewed as time-consuming by nurses and nurses may have the mindset that patients who are not medically educated lack the "expert" knowledge necessary to exercise selfdetermination in their care or that engagement does not result in positive patient outcomes (Burns, Bellows, Eigenseher, \& Gallivan, 2014; Nilsson, From, \& Lindwall, 2019).

Encouragingly, both patients and nurses in this study reported that the PPET provided useful information about the patient to the nurse and was helpful in planning individualized nursing care. Selman et al.

(2017) demonstrated that patients' engagement depended on the degree that communication, information, and support from their providers were tailored to their unique situations and preferences. This study, much like others, demonstrated that patient preferences for engagement in healthcare cannot be predicted based on 
demographical factors such as gender, education level, health perception, chronic illness load, and whether someone lives alone (Adams, Drake, \& Wolford, 2007). Older patients in this study scored items in the RE factor lower, which is consistent with less familiarity with use of the Internet and computers (Jerofke-Owen \& Dahlman, 2019). Older patients also tended to score the two items regarding involving family and friends in their care higher than their younger counterparts, again consistent with prior studies that showed older patients defined engagement in terms of how involved their family members were in addition to themselves (Etkind et al., 2018). Although age was a significant predictor of RE and FI factor scores in this study, it did not predict the other four factor scores. Use of the PPET in practice will enable healthcare providers to assess patient preferences in a methodological way while avoiding making assumptions that a patient may/may not exercise self-determination in their care based on demographics or illness-related factors (Selman et al., 2017). Lastly, patients reported that their answers could change over time based on their unique situations, stressing the necessity to assess patient preferences for engagement throughout the hospitalization and the importance of reconsidering engagement strategies as patient preferences change.

Future studies should test a shortened version of the PPET for widespread clinical utility. Although patients and nurses did not report a heavy testing burden of the PPET on completed usability surveys, the PPET would be more clinically useful and likely to be completed by healthcare providers if it was shortened. Patient physical and psychological condition, healthcare environment (ambulatory, emergency department, critical care, acute care), and length of time managing a health condition may affect patient preferences for engagement in healthcare (De las Cuevas \& Peñate, 2016; Hoerger et al., 2016), highlighting the need to assess patient preferences for engagement at different times in the illness trajectory or within different locations.

Options for how patient preferences for engagement in healthcare could be directly incorporated into the EHR should also be examined in future studies, as integration of these preferences electronically would allow all providers caring for the patient to access this valuable patient-reported data. Lastly, Swartwout et al. (2016) suggest the utility in assessing patient's readiness to engage in their healthcare and have developed the Person Engagement Index instrument, a model examining a patient's readiness to engage. How the index relates with the patient's preferences and subsequent engagement outcomes could help us understand how to better engage patients in an individualized, targeted manner.

\section{Limitations}

The study had some limitations. The study was conducted at one academic Magnet-designated medical facility with a predominantly White sample that was well educated and could speak English. Future studies should be conducted in other settings, such as settings with more diverse patients or more rural locations where patients may have a harder time accessing care and may have different preferences or abilities to engage in their healthcare or in an ambulatory setting, where patients may not have the unfamiliar hospital environment or acute health needs influencing their perceptions about their engagement in their healthcare. The instrument could also be professionally translated to other languages, so non-English-speaking patients could also benefit from reporting their preferences for engagement in their healthcare. Because education level can play a role in patient comfort with engaging in healthcare, future studies should make a conscious effort to enroll patients of varying education levels to examine if any differences in psychometric properties exist in that population.

Lastly, although the researchers examined the reliability, construct validity, and usability of a new tool, external criterion validation was not conducted because there is not a gold standard tool for measuring patient preference for engagement. Future studies of the PPET should examine associations of PPET scores with scores of other instruments measuring similar constructs such as patient activation or measures of autonomy. 


\section{Conclusion}

The newly developed PPET is a promising instrument to generate patient expression of preference for engagement in their care that can inform the delivery of individualized care for precision healthcare. The importance of assessing and not assuming patient preferences for engagement in healthcare is highlighted by the study finding that PPET factor scores were not significantly associated with patient demographics or illness factors. Both patients and nurses had favorable ratings of the effectiveness, efficiency, and satisfaction with the PPET. The PPET will benefit from further validation in other samples and settings such as with non-Englishspeaking patients, rural or ambulatory settings, or patients with lower levels of education or by testing a shortened, more clinically useful version. Areas of future research include the examination of how nurses use the PPET in care delivery and the effect of assessing patient preferences for engagement on the patient experience of engagement or patient outcomes, such as the actual engagement in various components of care, decreased adverse events, healthcare utilization, or quality of life.

\section{REFERENCES}

Adams J. R., Drake R. E., \& Wolford G. L. (2007). Shared decision-making preferences of people with severe mental illness. Psychiatric Services, 58, 1219-

1221. https://ps.psychiatryonline.org/doi/pdf/10.1176/ps.2007.58.9.1219

Agency for Healthcare Research and Quality. (2013). Guide to patient and family engagement in hospital quality and safety. Retrieved from http://www.ahrq.gov/professionals/systems/hospital/engagingfamilies/guide.html

Arora N. K., Ayanian J. Z., \& Guadagnoli E. (2005). Examining the relationship of patients' attitudes and beliefs with their self-reported level of participation in medical decision-making. Medical Care, 43, 865-872.

Boivin A., L'Espérance A., Gauvin F. P., Dumez V., Macaulay A. C., Lehoux P., \& Abelson J. (2018). Patient and public engagement in research and health system decision making: A systematic review of evaluation tools. Health Expectations, 21, 1075-1084. doi:10.1111/hex.12804

Bombard Y., Baker G. R., Orlando E., Fancott C., Bhatia P., Casalino S., ... Pomey M. P. (2018). Engaging patients to improve quality of care: A systematic review. Implementation Science, 13, 98. doi:10.1186/s13012018-0784-z

Bovaird J. A., \& Kozoil N. A. (2012). Measurement models for ordered-categorical indicators. In Hoyle R. H. (Ed.), Handbook of structural equation modeling (pp. 495-511). New York: Guilford Press.

Burns K. K., Bellows M., Eigenseher C., \& Gallivan J. (2014). 'Practical' resources to support patient and family engagement in healthcare decisions: A scoping review. BMC Health Services Research, 14, 175. doi:10.1186/1472-6963-14-175

Carman K. L., Dardess P., Maurer M., Sofaer S., Adams K., Bechtel C., \& Sweeney J. (2013). Patient and family engagement: A framework for understanding the elements and developing interventions and policies. Health Affairs, 32, 223-231. doi:10.1377/hlthaff.2012.1133

Clancy C. M. (2011). Patient engagement in healthcare. Health Services Research, 46, 389-393. doi:10.1111/j.1475-6773.2011.01254.x

De las Cuevas C., \& Peñate W. (2016). Validity of the control preferences scale in patients with emotional disorders. Patient Preference and Adherence, 10, 2351-2356. doi:10.2147/PPA.S122377

Degner L. F., Sloan J. A., \& Venkatesh P. (1997). The control preferences scale. Canadian Journal of Nursing Research, 29, 21-43.

Drenkard K., Swartwout E., Deyo P., \& O’Neil M. B. Jr. (2015). Interactive care model: A framework for more fully engaging people in their healthcare. Journal of Nursing Administration, 45, 503-510. doi:10.1097/NNA.0000000000000242

Dwamena F., Holmes-Rovner M., Gaulden C. M., Jorgenson S., Sadigh G., Sikorskii A., ... Olomu A. (2012). Interventions for providers to promote a patient-centred approach in clinical consultations. Cochrane Database of Systematic Reviews, 12. doi:10.1002/14651858.CD003267.pub2 
Eldh A. C., Luhr K., \& Ehnfors M. (2015). The development and initial validation of a clinical tool for patients' preferences on patient participation-The 4Ps. Health Expectations, 18, 2522-2535. doi:10.1111/hex.12221

Ende J., Kazis L., Ash A., \& Moskowitz M. A. (1989). Measuring patients' desire for autonomy: Decision making and information-seeking preferences among medical patients. Journal of General Internal Medicine, 4, 23-30. doi:10.1007/BF02596485

Enders C. K. (2010). Applied missing data analysis. New York: Guilford Press.

Etkind S., Bone A. E., Lovell N., Higginson I. J., \& Murtagh F. E. M. (2018). Influences on care preferences of older people with advanced illness: A systematic review and thematic synthesis. Journal of the American Geriatric Society, 66, 1031-1039. doi:10.1111/jgs.15272

Florin J., Ehrenberg A., \& Ehnfors M. (2008). Clinical decision-making: Predictors of patient participation in nursing care. Journal of Clinical Nursing, 17, 2935-2944. doi:10.1111/j.1365-2702.2008.02328.x

Frank C., Asp M., \& Dahlberg K. (2009). Patient participation in emergency care-A phenomenographic study based on patients' lived experience. International Emergency Nursing, 17, 15-22. doi:10.1016/j.ienj.2008.09.003

Graffigna G., \& Barello S. (2018). Spotlight on the patient health engagement model (PHE model): A psychosocial theory to understand people's meaningful engagement in their own health care. Patient Prefer Adherence, 12, 1261-1271. doi:10.2147/PPA.S145646

Hawley S. T., \& Morris A. M. (2017). Cultural challenges to engaging patients in shared decision making. Patient Education and Counseling, 100, 18-24. doi:10.1016/j.pec.2016.07.008

Hoerger M., Chapman B. P., Mohile S. G., \& Duberstein P. R. (2016). Development and psychometric evaluation of the Decisional Engagement Scale (DES-10): A patient-reported psychosocial survey for quality cancer care. Psychological Assessment, 28, 1087-1100. doi:10.1037/pas0000294

Hu L., \& Bentler P. M. (1999). Cutoff criteria for fit indexes in covariance structure analysis: Conventional criteria versus new alternatives. Structural Equation Modeling: A Multidisciplinary Journal, 6, 1-55. doi:10.1080/10705519909540118

International Standardization for Organization (1998). Ergonomic requirements for office work with visual display terminals (VDTs)-Part 11: Guidance on usability. ISO Standard 9241-11. Retrieved from http://www.iso.org/iso/catalogue detail.htm?csnumber=16883

James J. (2013). Health policy brief: Patient engagement. Health Affairs. Retrieved from https://www.healthaffairs.org/do/10.1377/hpb20130214.898775/full/healthpolicybrief 86.pdf.

Jerofke-Owen T., \& Dahlman J. (2019). Patients' perspectives on engaging in their healthcare while hospitalised. Journal of Clinical Nursing, 28(1-2), 340-350.

Jordan L. M. (2014). Self-management goals made simple (excerpts from 2014 PCMH pre-conference). The Joint Commission. Retrieved from https://www.jointcommission.org/assets/1/18/presentation ahc pcmh joint commission 2014 pcmh pre-conf-patient self-management.pdf

Luhr K., Eldh A. C., Nilsson U., \& Holmefur M. (2018). Patient Preferences for Patient Participation: Psychometric evaluation of the 4Ps tool in patients with chronic heart or lung disorders. Nordic Journal of Nursing Research, 38, 68-76. doi:10.1177/2057158517713156

Lynn M. R. (1986). Determination and quantification of content validity. Nursing Research, 35, 382-385. doi:10.1097/00006199-198611000-00017

Mokkink L. B., de Vet H. C. W., Prinsen C. A. C., Patrick D. L., Alonso J., Bouter L. M., \& Terwee C. B. (2018). COSMIN risk of bias checklist for systematic reviews of patient-reported outcome measures. Quality of Life Research, 27, 1171-1179. doi:10.1007/s11136-017-1765-4

Nilsson M., From I., \& Lindwall L. (2019). The significance of patient participation in nursing care-A concept analysis. Scandinavian Journal of Caring Sciences, 33, 244-251. doi:10.1111/scs.12609

Park H. S., Dailey R., \& Lemus D. (2002). The use of exploratory factor analysis and principal components analysis in communication research. Human Communication Research, 28, 562-577. doi:10.1111/j.1468-

2958.2002.tb00824.x 
Patient-Centered Outcomes Research Institute. (2013). Advisory panel on patient engagement. Retrieved from https://www.pcori.org/engagement/engage-us/join-advisory-panel/advisory-panel-patientengagement

Pelletier L. R., \& Stichler J. F. (2013). Action brief: Patient engagement and activation: A health reform imperative and improvement opportunity for nursing. Nursing Outlook, 61, 51-54. doi:10.1016/j.outlook.2012.11.003

Prey J. E., Woollen J., Wilcox L., Sackeim A. D., Hripcsak G., Bakken S., ... Vawdrey D. K. (2014). Patient engagement in the inpatient setting: A systematic review. Journal of the American Medical Informatics Association, 21, 742-750. doi:10.1136/amiajnl-2013-002141

Rosewilliam S., Roskell C. A., \& Pandyan A. D. (2011). A systematic review and synthesis of the quantitative and qualitative evidence behind patient-centred goal setting in stroke rehabilitation. Clinical Rehabilitation, 25, 501-514. doi:10.1177/0269215510394467

Rozenblum R., Lisby M., Hockey P. M., Levtizion-Korach O., Salzberg C. A., Lipsitz S., \& Bates D. W. (2011). Uncovering the blind spot of patient satisfaction: An international survey. BMJ Quality \& Safety, 20, 959-965. doi:10.1136/bmjqs-2011-000306

Selman L. E., Daveson B. A., Smith M., Johnston B., Ryan K., Morrison R. S., ... Higginson I. J. (2017). How empowering is hospital care for older people with advanced disease? Barriers and facilitators from a cross-national ethnography in England, Ireland and the USA. Age and Ageing, 46, 300-309. doi:10.1093/ageing/afw193

Swartwout E., Drenkard K., McGuinn K., Grant S., \& El-Zein A. (2016). Patient and family engagement summit: Needed changes in clinical practice. Journal of Nursing Administration, 46(3 Suppl), S11-S18. doi:10.1097/NNA.0000000000000317

Tobiano G., Marshall A., Bucknall T., \& Chaboyer W. (2015). Patient participation in nursing care on medical wards: An integrative review. International Journal of Nursing Studies, 52, 1107-1120. doi:10.1016/j.ijnurstu.2015.02.010

Weijters B., Baumgartner H., \& Schillewaert N. (2013). Reversed item bias: An integrative model. Psychological Methods, 18, 320-334. doi:10.1037/a0032121

Weingart S. N., Zhu J., Chiappetta L., Stuver S. O., Schneider E. C., Epstein A. M., ... Weissman J. S. (2011). Hospitalized patients' participation and its impact on quality of care and patient safety. International Journal for Quality in Health Care, 23, 269-277. doi:10.1093/intqhc/mzr002

\section{Keywords:}

acute care; measurement properties; patient participation; patient preference 